\title{
From Bodily Rights to Personal Rights
}

\author{
Thomas Douglas
}

The right to bodily integrity (RBI) may seem inapt for inclusion in this volume, which is supposed to address new human rights, for as A. M. Viens notes, the RBI is a long-standing fixture in the philosophical and legal discussion of rights. However, Viens does, I think, make a good case for the right's inclusion here. Not only does he note the increasing recognition of a new right to genital integrity derived from the more general RBI, he also argues for a new conceptualisation of the RBI itself: he argues that we ought to decompose the RBI into several constituent rights, delineated according to the different values from which they derive - rights to bodily autonomy, bodily dignity, bodily ownership, well-being, and so on. As he writes:

On this view, there would be no single RBI in play but a series of rights concerning the body, such as bodily autonomy, bodily privacy, bodily dignity, bodily well-being, etc. Accordingly, there is no RBI per se, but a collection of bodily rights that seek to preserve or protect different aspects of the body that are related but not identical to each other. One way to understand this option would be akin to how we understand property as a bundle of rights. On this view, bodily integrity is most properly viewed, metaphorically, as a 'bundle of sticks' with each stick representing an individual bodily right. We could say someone has a so-called RBI in a manner of speaking insofar as they possess a set of rights related to their body. ${ }^{1}$

The constituent rights that make up this bundle would, Viens suggests, differ from one another not only in their justificatory source, but also in their content: they would protect against different kinds of bodily interference and, in some cases, bodily neglect. The RBI would then be understood simply as the conjunction of these constituent rights.

Viens does not himself claim any great novelty for his way of conceptualising the RBI. However, in this commentary I want to suggest that he in fact understates the novelty of his approach. I will argue that at least three of the 'constituent' rights mentioned by Viens - those deriving from ownership, autonomy and privacy - are more substantially different from the (traditionally understood) RBI than Viens acknowledges. Not only are they different from that right in that they are tied to particular justifying values and particular forms of bodily interference or neglect, they are also different in their boundaries. Whereas the protection provided by the (traditionally understood) RBI extends only to the boundary of the body, rights deriving from ownership, autonomy and privacy extend further; they protect against some interferences

A. M. Viens, in this volume, pp. $374 \mathrm{f}$.

Viens reserves the claim to novelty for the right to genital integrity, discussed in the penultimate section of his chapter. 
that are not interferences with the body, though they are interferences with the person. Given this, I will suggest that these rights are not aptly characterised as bodily rights at all. Rather, they should be conceived as personal rights that encompass both bodily and mental integrity.

I first make this argument with respect to rights deriving from ownership. I then show how it can be extended to rights deriving from autonomy and privacy. Before commencing the argument, though, I briefly explain why I think it is an argument worth making.

\subsection{THE SIGNIFICANCE OF THE BODY}

The body is often treated as having a special moral - and indeed legal - significance, such that interfering with a person's body is more problematic than interfering with her life in other ways, for example through altering her natural or social environment. ${ }^{3}$ This is easily seen within the sphere of criminal justice, where extreme forms of environmental interference - such as those entailed by incarceration - are widely accepted, yet interventions that invade the body - such as compulsory chemical castration or methadone treatment - are highly controversial. ${ }^{4} \mathrm{~A}$ similar situation obtains in public health. In the context of pandemic control, quarantine - a very restrictive external intervention - is often thought more defensible than, for example, compulsory injections of antibiotics or vaccines.

This special significance given to the body makes sense if we accept that people possess rights against bodily interference and that we possess no similarly strong rights against other forms of interference. My argument below casts doubt on this view and thus undermines one way of justifying the special significance of the body. ${ }^{5}$ argue that at least some of our rights that protect against bodily interference or neglect - those deriving from ownership, autonomy and privacy provide equally strong protection that extends beyond the body too.

Viens concedes that, in treating the right to bodily integrity as a cluster of heterogenous constituent rights, he is offering 'a piecemeal and perhaps diminished account of bodily integrity'. ${ }^{6}$ However, he suggests that his account nevertheless allows 'for the preservation of the essence of what bodily rights seek to protect'. I I will be seeking to cast doubt on this latter view, since I think that part of this essence that bodily rights seek to protect is the special significance of the body. ${ }^{8}$

Throughout, I focus on moral rather than legal rights, since legal rights lie beyond my sphere of competence, but let me briefly comment on the possible legal implications of my argument. Does my argument imply that the law should reject bodily rights in favour of personal rights? Does it imply that the law should confer no special legal significance on the body? The answer is not straightforward, for there can be reasons for recognising legal rights that do not correspond

3 For a judicial expression of this view, see R (on the application of Justin West) v. The Parole Board [2002] EWCA Civ 1641; [2003] 1 W.L.R. 705 at 49, per Hale LJ in her dissenting judgment.

4 See, for example, chapters by C. Bennett, E. Shaw, J. C. Bublitz, and E. McTernan in D. Birks and T. Douglas (eds.), Treatment for Crime: Philosophical Essays on Neurointerventions in Criminal Justice, (Oxford: Oxford University Press, 2018).

5 My argument here parallels one made by J. Anderson in his 'Neuro-Prosthetics, the Extended Mind, and Respect for Persons with Disability', in M. Düwell, C. Rehmann-Sutter and D. Mieth (eds.), The Contingent Nature of Life: Bioethics and Limits of Human Existence (Heidelberg: Springer, 2008). Anderson's argument against the special moral significance of the boundaries of the body is more general than mine: it does not focus specifically on moral rights.

6 Viens, in this volume, p. 373

Ibid., p. 373 .

I say that my argument casts doubt on the view, rather than being inconsistent with it, since it is possible that some of the other bodily rights that Viens' mentions - i.e. those not deriving from ownership, autonomy and privacy - do confer special significance on the body. I do not think that they do, but I cannot argue this here. 
to moral rights. I am not convinced that a patent-holder possesses a moral right to extract monopoly profits from her invention, but there may still be economic reasons to grant her such a legal right. Similarly, there may be pragmatic reasons to confer legal rights that provide specific protection to the body. However, one reason - and, in my view, the usual reason - to recognise a legal right is that there is an underlying moral right. Thus, if there are no moral rights that specifically protect the body - as I believe Viens' argument implies - this undermines one possible reason for conferring legal rights specific to the body.

\subsection{RIGHTS OF SELF-OWNERSHIP AND THE EXTENDED MIND}

Viens suggests that we may have rights over our bodies that derive from ownership. But what is it, fundamentally, that we own? In virtue of our owning what do we have rights over our bodies? The standard answer, normally traced (at least) to John Locke, invokes our ownership of our selves or our persons (I take the two to be equivalent) - our rights of self-ownership. It might be thought that, since our selves clearly include our bodies, these rights will entail that we also have property rights over our bodies. And since property rights normally include rights against interference with our property, these property rights might seem to imply a right against bodily interference.

Our selves do not only consist of our bodies, however. Our minds are certainly also part of our selves. Indeed, some of the most influential proponents of self-ownership made it clear that this entailed ownership of the mind as well as the body. J. S. Mill held that: 'Over himself, over his own body and mind, the individual is sovereign'. ${ }^{9}$ For Locke, there was even a sense in which ownership of the mind was primary, for he thought that we originally acquire ownership of our selves through the mental action of taking responsibility for our actions..$^{10}$

Of course, there are large philosophical disagreements concerning the relationship between mind and body, and these may have implications for how we should think about rights of selfownership. On some views - physicalist views - our minds are just part of our bodies; our minds are, or can be reduced to, our brains, or parts of our brains." But on other views, minds are not merely body parts. For example, on one widely held view in philosophy, our minds are distinct from, though wholly determined by, our brain states, in much the same way that a statue is distinct from, though wholly determined by, the lump of clay from which it has been sculpted. On this view, our minds emerge from our brains. On another view, they emerge not only from our brains but also from certain external objects. ${ }^{12}$ Indeed, according to the extended mind thesis, these external objects that support our cognition stand in the same relation to our minds as do our brain states. ${ }^{13}$ On one influential formulation of this view, due to Neil Levy:

the mind is not wholly contained within the skull ... but instead spills into the world. [It] should be understood as the set of mechanisms and resources with which we think, and that set is not limited to the internal resources made up of neurons and neurotransmitters. Instead, it includes

9 J. S. Mill, On Liberty, ed. by D. Spitz (Toronto: W. W. Norton, [1895] 1975), p. 11.

10 G. Herbert, A Philosophical History of Rights (Abingdon and New York: Routledge, 2017), p. 119.

${ }^{11}$ For classic statements of the view, see U. T. Place, 'Is Consciousness a Brain Process?' (1956) 47 British Journal of Psychology 44; H. Feigl, "The "Mental" and the "Physical"', in H. Feigl, M. Scriven and G. Maxwell (eds.), Concepts, Theories and the Mind-Body Problem, Minnesota Studies in the Philosophy of Science, vol. II (Minneapolis: University of Minnesota Press, 1958); D. Lewis, 'An Argument for the Identity Theory' (1966) 63 Journal of Philosophy 17.

${ }_{12}$ Both of these views are variants of 'emergentism'. For a classic statement of this view, see C. D. Broad, The Mind and Its Place in Nature (London: Routledge and Kegan Paul, 1925).

13 A. Clark and D. Chalmers, 'The Extended Mind' (1998) 58 Analysis 7. 
the set of tools we have developed for ourselves - our calculators, our books, even our fingers when we use them to count. ${ }^{14}$

If the extended mind thesis holds, then there is a straightforward sense in which, if someone interferes with my smartphone or diary, she interferes with my mind, and thus my self, and thus infringes my rights of self-ownership. ${ }^{15}$ This is true even though no bodily interference is involved. Interfering with my body becomes just one among other ways in which a person can interfere with my self. Thus, we see that - on the extended mind thesis - the protection provided by rights of self-ownership extends beyond the boundaries of the body.

\subsection{RIGHTS OF SELF-OWNERSHIP AND THE NON-EXTENDED MIND}

In fact, it is possible to generate a similar result even if the extended mind thesis does not hold. Consider the view, mentioned above, that the mind is distinct from but wholly determined by our brain states. Or consider the physicalist view that the mind is just (part of) the brain. On these views, anything that affects our minds must also affect our brains and thus our bodies; the only way to induce a change to someone's mental states is to induce a change to their brain states. It might therefore seem that any sort of mental interference will, on this view, also involve bodily interference. Thus, we can capture all interference with the self through the concept of interference with the body.

A difficulty with this view, however, is that it is doubtful that all interventions that affect the body involve bodily interference. On the views about the relationship between mind and brain that I am currently assuming, everything that influences the mind must also influence the brain and thus the body - it must cause some alteration to bodily states or processes. But something can influence the body without interfering with it, where that is taken to imply that the right to bodily integrity is implicated. By breathing out carbon dioxide molecules, we influence the bodily states of others in the same room, but it is not clear that we interfere with their bodies. Interference may require, for example, that the influence be intentional, that it meet some threshold level of significance, or that it be unwanted. Similarly, something can influence the mind without interfering with it. Interference requires more than mere influence. This leaves us scope to hold that something could influence both the body and the mind, but interfere only with the mind, and indeed that seems a plausible thing to say about certain interventions.

Consider historical forms of brainwashing, such as hypnosis and aversion therapy. These interventions clearly interfere with the mind and thus the self. They thus plausibly infringe rights of self-ownership. But do they also interfere with the body? To the extent that (1) these interventions affect a person's thoughts and feelings, and (2) those thoughts and feelings are fully determined by brain states, then these interventions must have an impact on the body: they must affect a person's brain states. But even if we accept this, we may find it implausible to think that there is any bodily interference here. We may wish to say that brainwashing techniques influence both the brain and the mind, but interfere only with the mind, perhaps on the basis that only the mental effects are intended by the brainwasher. Perhaps to interfere with something we have to intentionally influence it. Even some interventions that exert a direct, biological effect

${ }^{14}$ N. Levy, Neuroethics (Cambridge: Cambridge University Press, 2007), p. 29.

15 I assume here that the self encompasses all of the mind. For a contrasting view, see T. Buller, 'Neurotechnology, Invasiveness and the Extended Mind' (2013) 6 Neuroethics 593. I agree with Buller that it is an open question whether the self encompasses all of the mind; I simply doubt that there is any persuasive positive argument for the view that it does not. 
on the brain may interfere with the mind, and thus the self, without interfering with the body. Consider transcranial direct current stimulation (tDCS). This involves subjecting the brain to a very small electric current using electrodes placed on the scalp. It can modulate various aspects of cognitive performance and in theory at least could induce particular thoughts and feelings.

Now tDCS, if done without someone's consent, would surely involve mental interference and be highly threatening to the self; if we have property rights over our selves, then tDCS surely infringes them. Yet it is less clear that tDCS involves interference with the body - indeed, it is often described as a 'non-invasive' form of brain stimulation, and we can imagine a version of tDCS that would not even involve bodily contact (suppose the electrodes could be kept a millimetre away from the scalp). ${ }^{16}$ Here again, as with brainwashing, there is clearly both mental and bodily influence. But again, one might be able to claim that there is mental but no bodily interference. For example, one might claim that the degree of physical influence of tDCS is too insignificant to qualify as interference, whereas the degree of mental influence is much more significant. (I should say that I am not personally persuaded by this suggestion; I think we should regard tDCS as invoking both mental and bodily interference. The physical impact of tDCS is of a 'brute' physical variety and seems to differ from paradigmatic forms of bodily interference - such as the performance of a surgical procedure on someone - chiefly in that the physical impact in tDCS occurs through diffuse and invisible means. It seems doubtful to me that its diffuseness or invisibility could prevent it from involving bodily interference, and I am thus tempted to the view that tDCS does involve bodily interference. My point here is just that there are live alternative views available; it is at least reasonable to hold that tDCS involves no bodily interference.)

In both cases - brainwashing and tDCS - it seems possible to make sense of the thought that these interventions involve mental interference, and thus infringe rights of self-ownership, though they involve no bodily interference and thus do not implicate bodily rights.

\subsection{RIGHTS OF AUTONOMY AND RIGHTS OF PRIVACY}

I have been suggesting that rights of self-ownership protect against non-bodily forms of interference. I now want to suggest that a similar claim is true of two other kinds of rights mentioned by Viens - rights deriving from autonomy (henceforth simply 'rights of autonomy') and rights deriving from privacy ('rights of privacy'). Viens suggests that the cluster of bodily rights that protect our bodies might include rights of autonomy and rights of privacy, but I will argue that there is no reason to think that there are rights of autonomy or rights of privacy that specifically protect the body: rights of autonomy and privacy that protect the body also protect us against some forms of treatment that do not implicate the body.

Consider first autonomy. Autonomy is normally understood as requiring control over (or governance of) one's life. If someone interferes with my body without my consent (or perhaps even merely develops the power to do so), they have interfered with my autonomy, because they have reduced the degree to which I control one aspect of my life: the state or functioning of my body.

But there are questions about the scope of control that autonomy requires. Suppose my best friend falls head-over-heels in love and no longer has any time for me, with the result that I feel hurt and rejected. My friend has affected how my life goes and has plausibly diminished my

${ }^{16}$ For a discussion of whether bodily touching is sufficient for infringing a legal right to bodily integrity, see J. Herring and J. Wall, 'The Nature and Significance of the Right to Bodily Integrity' (2017) 76 The Cambridge Law Joumal 566 at 572 . 
control over how it goes, but he has not interfered with my autonomy. The romantic life of my best friend simply does not fall within the scope of my autonomy, even when it affects me very much.

What does lie within the scope of my autonomy? Over what must I have control to have autonomy? The obvious and I think most plausible answer is that I must have control over my self. But this leads us back to the argument advanced in the preceding sections: my self includes not (only) my body, but (also) my mind. So any right to autonomy that I possess must surely protect my mind as well as my body. Yet there are many interventions that reduce my control over my mind without in any meaningful way reducing my control over my body. Subliminal imagery may induce mental states that I cannot resist, and thus reduce my control over my mind, but we would not normally think that it reduces my bodily autonomy.

Similar thoughts apply - and perhaps even more clearly - to rights of privacy. Privacy requires the absence of certain kinds of access or observation. It requires that others abstain from accessing or observing certain aspects of my life. Which aspects exactly? This is a difficult question, but it is surely clear that someone can invade my privacy without accessing or observing my body in any way: reading a person's diary without their consent does not implicate their body, but it is a paradigmatic invasion of privacy, perhaps because reading someone's diary involves (possibly indirectly) accessing their self. At the very least, privacy seems to extend to cover parts of the self that lie beyond the body. Thus, rights of privacy should protect not only against accessing or observing the body, but also against accessing and observing non-bodily aspects of the self.

\subsection{PERSONAL RIGHTS}

Nothing I have said undermines Viens' claim that we possess rights deriving from self-ownership, autonomy and privacy, and that these rights protect our bodies against certain ways of treating our bodies. However, if my argument is correct, these rights also protect us against interventions that do not implicate the body in any rights-relevant way, but do implicate the mind and thus the self. Moreover, there seems no reason to suppose that the mental protections provided by these rights are any weaker than the bodily protections. ${ }^{17}$ After all, ownership, autonomy and privacy of our minds are at least as important to most of us as ownership, autonomy and privacy of our bodies. So it seems arbitrary to pick out only the aspects of these rights that protect the body, as we do if we refer to them as bodily rights. Moreover, if my argument is sound, these rights will not be able to play the role that bodily rights have often been thought to play: the role of giving the body a special moral significance.

My suggestion, then, is that we should think of these rights not as bodily rights at all, but as rights over the self or person - as personal rights. This, I think, would direct our attention to the important and neglected issue of the protection that they provide to the mind. While my above arguments suggest that the body does not deserve the prominent place that it has enjoyed in the philosophical rights discourse, they also suggest that there is a need for more attention to be paid to ways in which our rights protect our minds. This is a need that has been recognised in Article 3 of the Charter of Fundamental Rights of the European Union, which asserts a right

${ }_{17}$ It may be that Viens would accept and welcome this implication of his view, for he concedes that 'transgressing bodily integrity is likely best not thought about as a distinctive form or category of wrongdoing' (Viens, in this volume, p. 377). However, he regards this concession as consistent with his view that his account of bodily rights preserves the essence of the RBI. This is where I disagree with him. 
to 'integrity of the person', glossed as a right to 'physical and mental integrity'. ${ }^{18}$ It has also been recently highlighted by theorists of the law. ${ }^{19}$ However, the idea that we possess a moral right to mental integrity has little philosophical presence, leaving the corresponding legal right with weak philosophical foundations.

Of course, my suggestion that the boundaries of the body have no special moral significance also has more direct, practical implications. For example, it suggests that we ought to reconsider our practice of preferring mental interference to bodily interference in fields such as public health, forensic psychiatry and criminal justice. It may be that mental interference is just as threatening to self-ownership, autonomy and privacy as is bodily interference, and to the extent that our rights derive from those values, it may involve equally serious rights infringements.

${ }_{18}$ Charter of Fundamental Rights of the European Union, Nizza, 7 December 2000, in force 1 December 2009, OJ 2012 No. C $326 / 2$.

19 See, for example, R. Merkel and J. C. Bublitz in their 'Crimes Against Minds: On Mental Manipulations, Harms and a Human Right to Mental Self-Determination' (2014) 8 Criminal Law and Philosophy 51; M. Ienca and R. Andorno, 'Towards New Human Rights in the Age of Neuroscience and Neurotechnology' (2017) 13 Life Sciences, Society and Policy 1. See also J. C. Bublitz, in this volume; S. Michalowski, in this volume. 